\title{
Living Actively for Good Health: Children ${ }^{1}$
}

Jennifer Hillan²

For good health, children need to be active every day. There's no need for fancy bikes or highpriced shoes, just an active imagination! Read on to learn why physical activity is important and how you can help your child enjoy an active lifestyle.

\section{What is Physical Activity and Why is it Important?}

Physical activity is any body movement that uses energy. It includes all kinds of activities such as sports, walking, biking, dancing, and active chores like vacuuming, raking, and washing the car.

Regular physical activity helps build strong muscles and bones. It also helps improve self-esteem.

\section{How Active Should Kids Be?}

Kids should be active at least 60 minutes each day. It doesn't have to be all at once. Young children have short attention spans so they may have several short bursts of activity during the day. It all adds up!

\section{How Can I Help My Child be More Active?}

$\checkmark$ Children like to have fun! Find an activity your child enjoys and let him do it often.

$\checkmark$ Set a good example and play actively with your child.

$\checkmark$ Limit time spent watching TV and playing video games. Find ways your child can be physically active inside and outside.

$\checkmark$ Plan family trips to local hiking trails, parks, and public swimming pools.

$\checkmark$ Walk or bike together to and from school.

Let your child take a 10minute physical activity break from her homework.

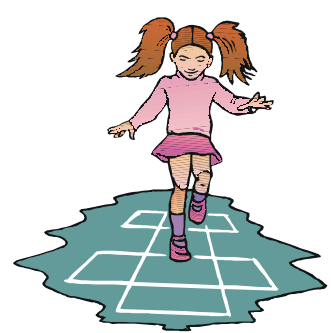

1. This publication is FCS8754-Eng, one of a series of the Department of Family, Youth and Community Sciences, Florida Cooperative Extension Service, Institute of Food and Agricultural Sciences, University of Florida. Publication date: August 2002. Reviewed by Anne Kendall, PhD, RD, LD/N, lecturer, Department of Food Science and Human Nutrition and Sergio Romero, MS, ATC, Department of Family, Youth and Community Sciences. Please visit the EDIS Web site at http://edis.ifas.ufl.edu

2. Jennifer Hillan, MSH, RD, LD/N, coordinator, Educational/Training Programs, Department of Family, Youth and Community Sciences, Cooperative Extension Service, Institute of Food and Agricultural Sciences, University of Florida, Gainesville, 32611. 


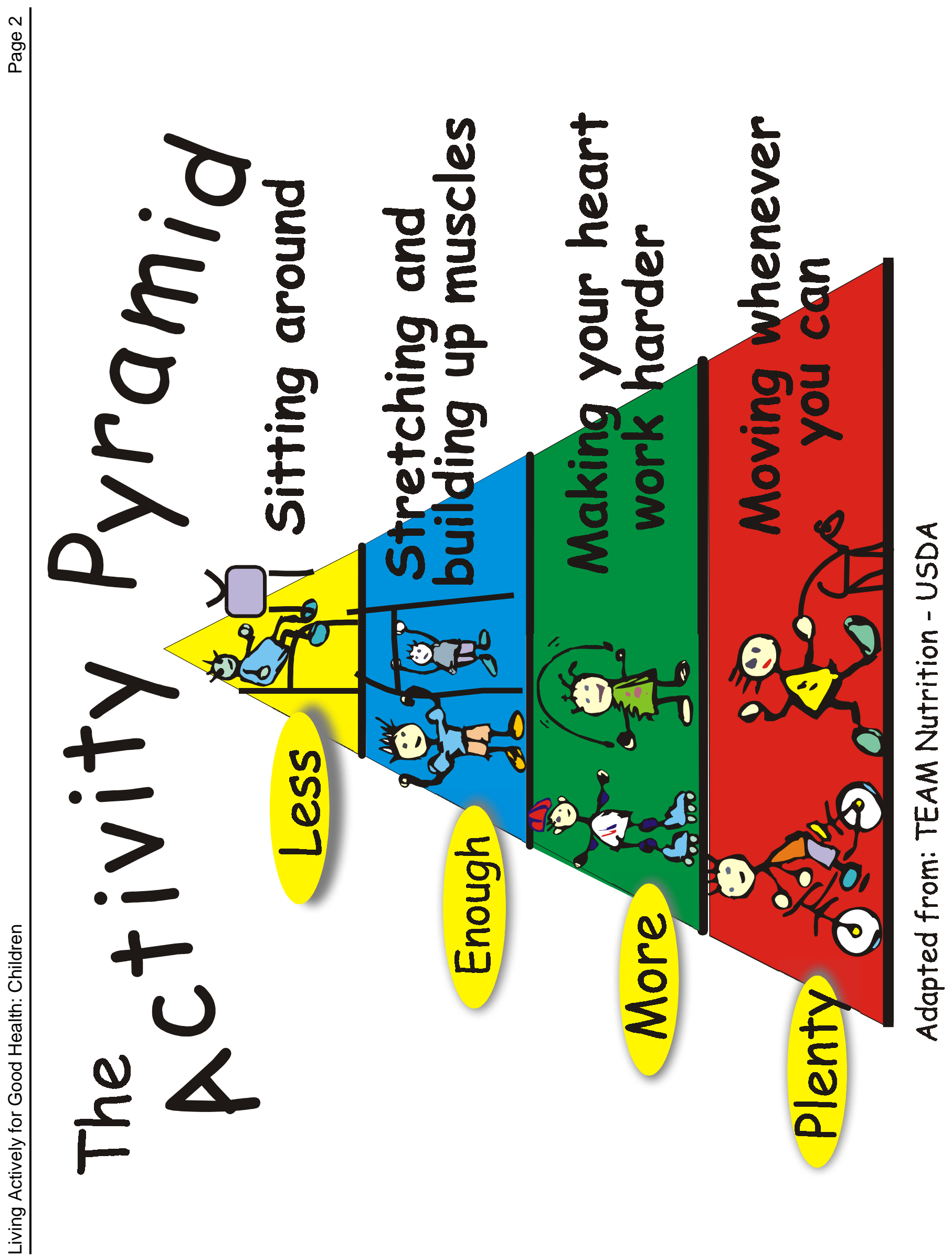

